EESTI NSV TEADUSTE AKADEEMIA TOIMETISED. XVIII KÖIDE

KEEMIA * GEOLOOGIA, 1969, Nr. 2

ИЗВЕСТИЯ АКАДЕМИИ НАУК ЭСТОНСКОЙ ССР. ТОМ ХVII

ХимИЯ * ГЕОЛОГИЯ. 1969, № 2

9. ЛИИВРАНД

\title{
О ПРИМЕНЕНИИ ФЛОРИСТИЧЕСКОГО АНАЛИЗА И МЕТОДА ВАРИОГРАММ ПРИ ИНТЕРПРЕТАЦИИ РЕЗУЛЬТАТОВ СПОРОВО-ПЫЛЬЦЕВОГО АНАЛИЗА НА ПРИМЕРЕ РАЗРЕЗА ХАРИМЯЭ (ЮЖНАЯ ЭСТОНИЯ)
}

Наиболее трудным в спорово-пыльцевом анализе является выделение переотложенной пыльцы от синхронной с осадком. Особенно трудно это, когда пыльцевые зерна близки по возрасту, например в случае перемешивания четвертичных спорово-пыльцевых комплексов разного возраста. Именно четвертичная пыльца чаще всего встречается в плейстоценовых отложениях в переотложенном виде, что подтверждают и анализы морен, В моренах и межморенных перигляциальных отложениях очень часто встречается пыльща межледниковых растекий (Малясова, Клейменова, 1965). Присутствие такой пыльцы затрудняет восстановление нстинной картины развития растительности. Поэтому выделение переотложенной пыльцы совершенно необходимо, если мы хотим по данным спорово-пыльцевого анализа судить о климате и сделать правильные стратиграфические выводы. Задача эта нелегкая. На первых порах некоторые исследопатели пытались решать вопрос, исключая нз подсчета пыльцу плохой сохранности, так как можно думать, что в процессе переотложения сохранность пыльцы ухудшается. Но это лишь частичное решение вопроса. Во-первых, не вся переотложенная пыльца имеет плохую сохранность, во-вторых, не все пыльцевые зерна плохой сохранности являются переотложенными. Установлено, что недоразвитая пыльца может обладать многими признаками так называемой пыльцы плохой сохранности, она часто смята, имеет стекловидный блеск, у нее еще отсутствуют четко выраженные морфологические признаки (Ананова, 1966). А переотложенная из межледниковых отложений пыльца морфологически развита, но часто механически повреждена - разорвана, смята. Таким образом, так называемая пыльца плохой сохранности может включать пыльцу действительно переотложенную, а также пыльцу синхронную с ней, но незрелую. Поэтому выделение пыльцы плохой сохранности из подсчета не давало желаемых результатов. В конечном итоге все же получались спорово-пыльцезые спектры смешанного характера, делать выводы по которым было еще труднее, так как контрасты между разновозрастными компонентами сглаживались. В результате этого разновозрастные спектры ошибочно относились к единому комплексу.

Переотложенную пыльцу можно легко выделить с помощью разработанного В. Гричуком специального варианта эколого-географического dнализа флоры, при котором анализируется как экология, так и современное географическое распространение таксонов, установленных в составе спорово-пыльцевых спектров (Гричук, 1969). Основой такого анализа является достаточно полное определение видов спор и пыльцы, проводимое одинаково по всему разрезу. Кроме обыкновенных споровопыльцевых диаграмм, составляются и флористические диаграммы, на которые все определенные виды наносятся по экологическим группам. В. Гричук (1969) выделяет следующие экологические группы: 
A. Термофильные и умеренно термофильные гигро- и гидрофиты.

Б. Лесные мезофиты:

1) термофильные,

2) умеренно термофильные,

3) микротермы (преимущественно сибирские виды).

В. Тундровые и северобореальные мезо- и ксерофиты:

1) виды, существующие в условиях малоконтинентального климата,

2) виды, распространенные преимущественно в областях с континентальным климатом.

Г. Элементы «пионерной» растительности (обитатели нарушенных и несформировавшихся почв, каменистого и песчаного субстрата):

1) мезофиты,

2) ксерофиты.

Д. Галофиты:

1) виды прибрежно-морских и континентальных местообитаний,

2) виды только континентальных засоленных местообитаний.

Руководствуясь работой В. Гричука, автор вторично просмотрела образцы разреза Харимяэ, впервые опубликованного в книге «Нижний плейстоцен ледниковых районов Русской равнины» (Каяк, Лийвранд, 1967). Видовые определения проводились по всему разрезу и притом более основательно, чем раньше. Особое внимание уделялось семейству маревых, экология представителей которых очень разнообразна и позволяет сделать важные выводы о генезисе осадков. Многие видовые определения проверены одним из опытнейших морфологов спор и пыльцы М. Моносзон. Результаты спорово-пыльцевого анализа графически интерпретированы на обыкновенной спорово-пыльцевой диаграмме (рис. 1).

На рис. 3 изображено количество всех древесных пород отдельно, причем количество видов берез вычислено в процентах от суммы пыльцы деревьев, а на рис. 1 - в процентах от общего количества определенных видов пыльцы рода Betula. Изображение видов пыльцы Betula разными способами позволяет лучше проследить за изменением кривых этой очень важной группы древесных пород. На рис. 3 отмечено также присутствие некоторых видов тундровых и степных растений. Все важнейшие виды и роды по экологическим группам, выделенным В. Гричуком, приведены на рис. 2. В таблицу включены цифровые данные спорово-пыльцевого анализа изучаемого разреза.

На спорово-пыльцевой диаграмме (рис. 1) отражены вся найденная пыльца и все споры, в результате чего получилась диаграмма сравнительно смешанного характера. По всему разрезу встречается пыльца термофильной флоры $(5-15 \%)$, характерной для межледниковий. Одновременно с ней встречаются и тундровые виды Betula nana L. (20-80\%), Lycopodium pungens La Pyl., L. apressum (Desv.) Petr., Artemisia arctica Less., A. borealis Pall. вместе с представителями некоторых степных ксерофитов - Eurotia ceratoides (L) C. A. M., Polycnemum sp., Ephedra sp. Совместное обитание тундровых растений с некоторыми степными элементами считается характернейшей особенностью гляциальных флор (Гричук, 1969; Сукачев, 1968). Но сосуществование холодолюбивой гляциальной и теплолюбивой межледниковой флор экологически и географически никак не совместимо. Один из этих двух спорово-пыльцевых комплексов должен быть переотложенным. Принимая во внимание гораздо меньшую способность продуцирования пыльцы у недревесных растений по сравнению с межледниковыми древесными породами, присутствие такого большого количества пыльцы 


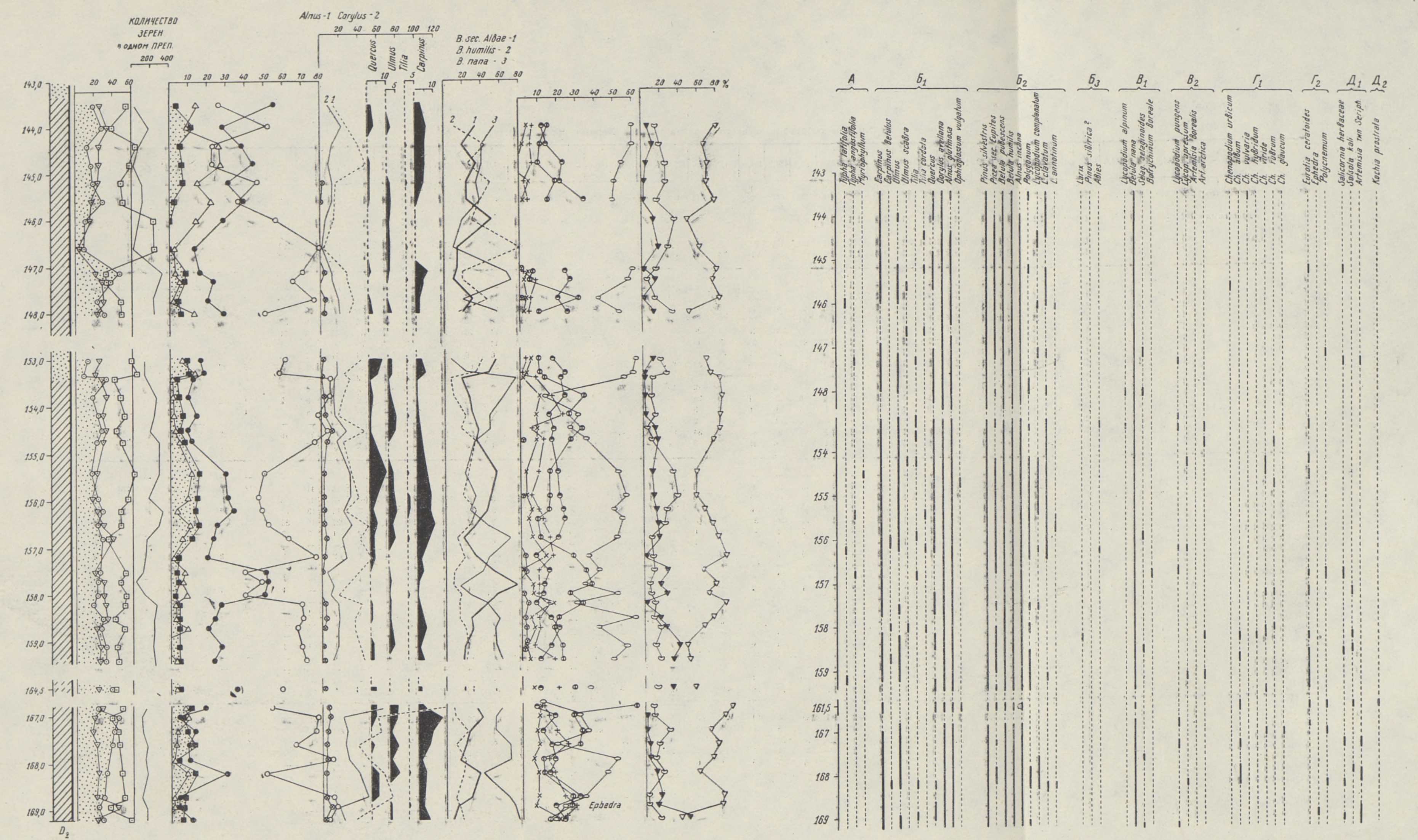

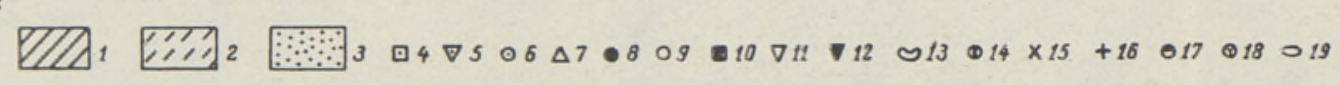




\section{Результаты спорово-пыльцевого анализа разреза Харимяэ (скв. 323).}

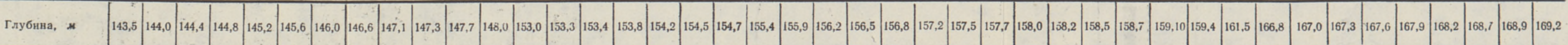

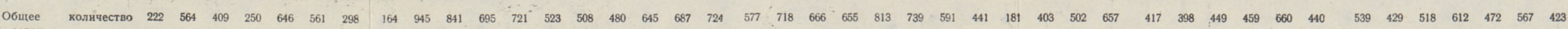

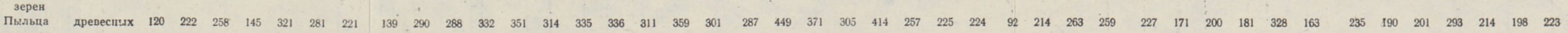

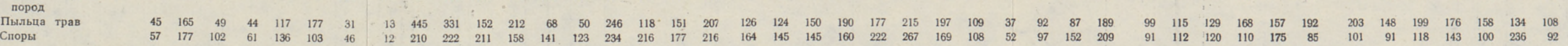

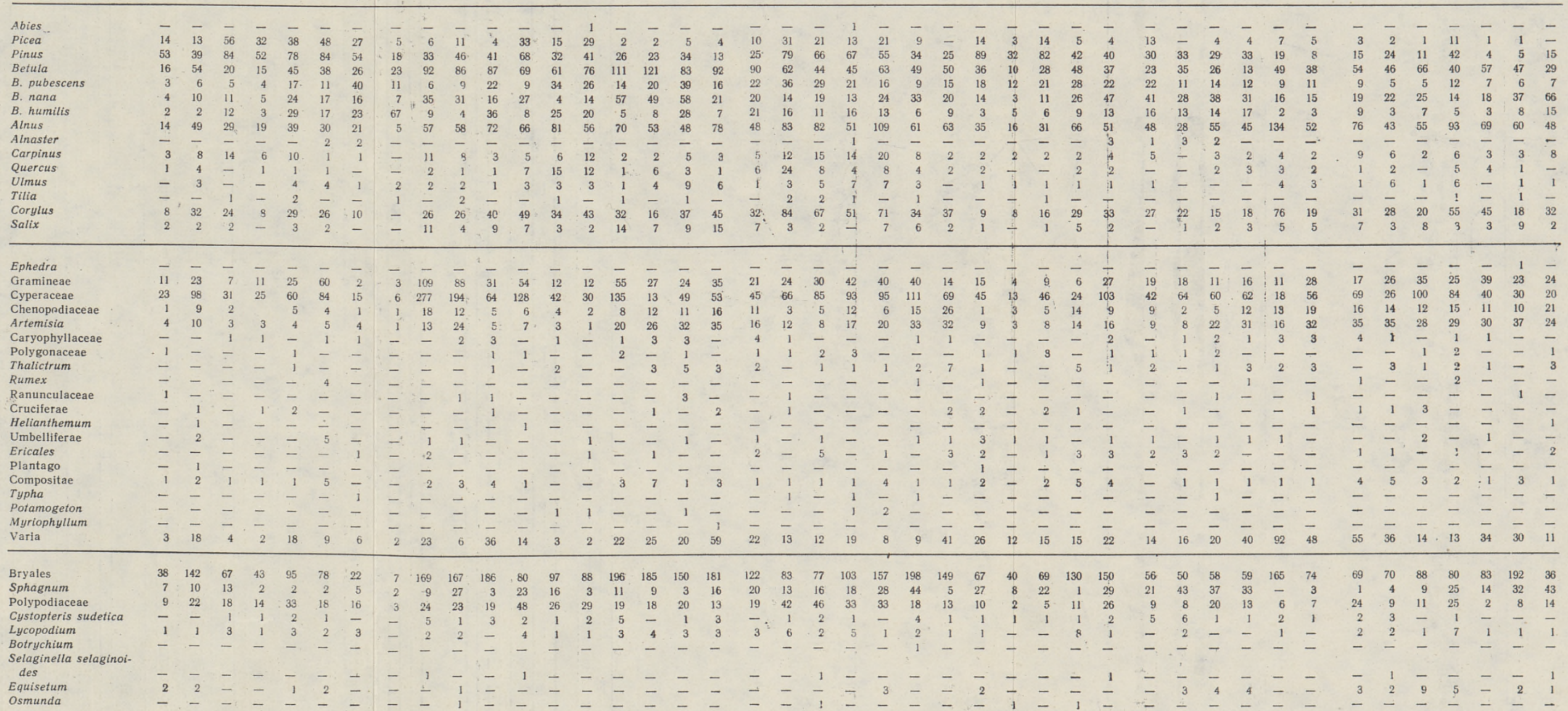



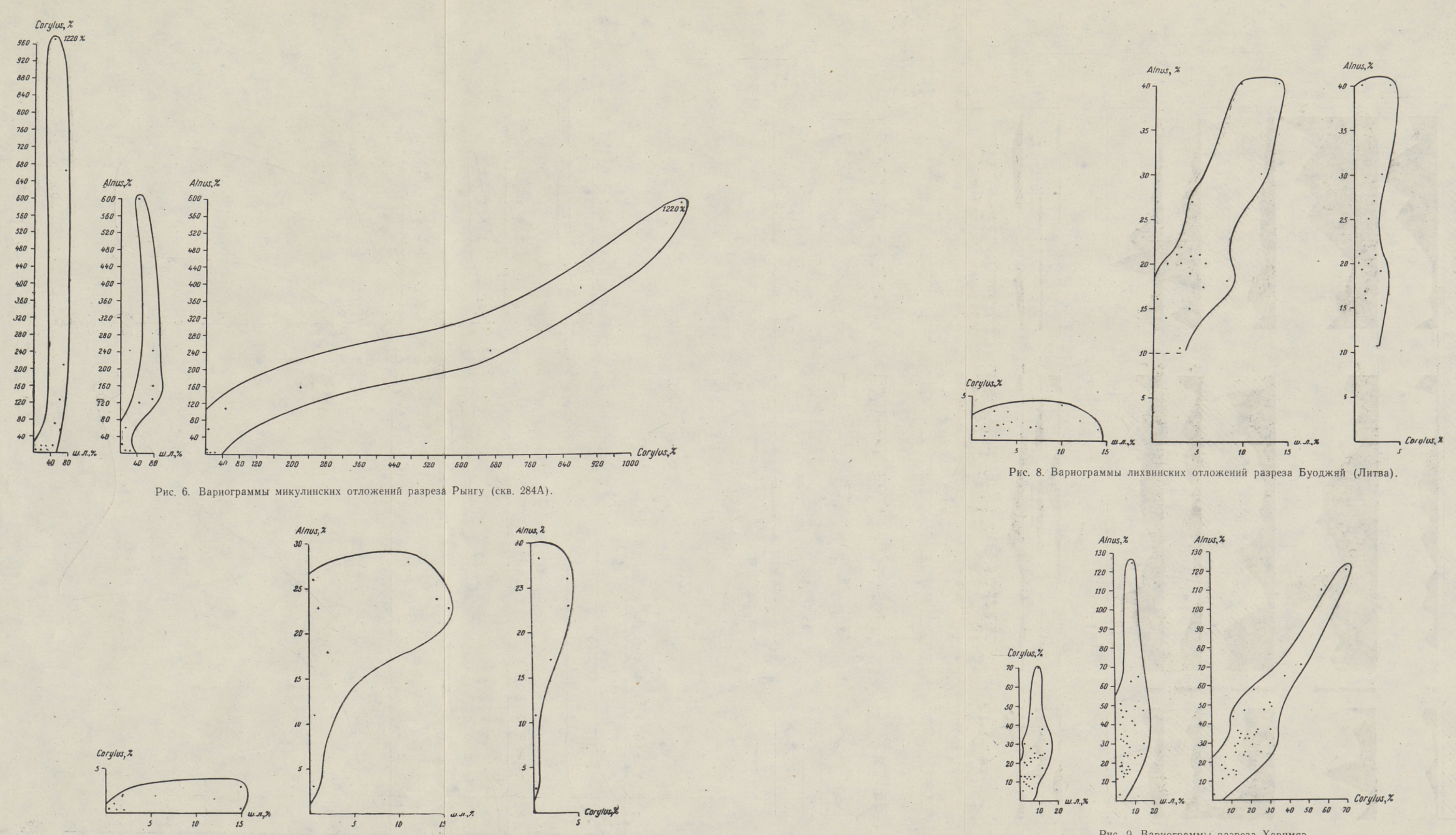

Рис. 7. Вариограммы лихвинских отложений разреза Б. Коша у погоста НІлья ПІророк.

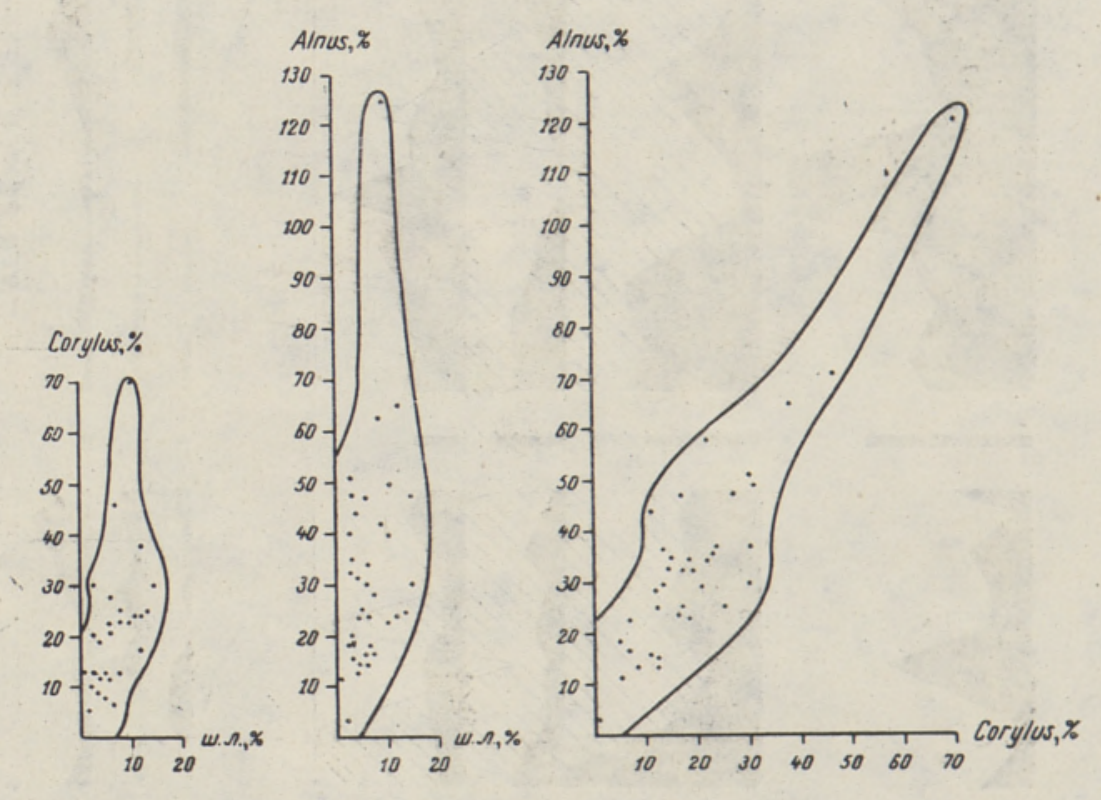

Рис. 9. Вариограммы разреза Харимяэ. 
гляциальных растений в переотложенном виде в данном случае кажется неправдоподобным. Скорее наоборот. Продуцируемая в огромном количестве пыльца межледниковых древесных пород может встречаться в переотложенном виде гораздо чаще. Этому способствуют и более интенсивные экзарационные процессы во время ледниковых эпох по сравнению с межледниковыми. В данном случае не наблюдается также никакой закономерности и порядка в кульминации пыльцы широколиственных пород. Она встречается случайно. Некоторое увеличение количества пыльцы широколиственных пород не сопровождается уменьшением содержания пыльцы травянистых растений и существенным уменышением количества пыльцы Betula nana L. Но изменения пыльцевой кривой B. nana L. хорошо согласуются с изменениями содержания пыльцы других тундровых и степных видов. С увеличением количества пыльцы B. nana L. состав тундровых и степных видов становится разнообразнее и они встречаются чаще, а с уменьшением - видовой состав последних беднеет и они встречаются реже.

Таким образом, синхронными с осадком в данном случае можно счи тать только спорово-пыльцевые спектры гляциальных флор, а термофильные элементы (экологические группы $A$ и $E_{1}$, частично $E_{2}$ на рис. 2) являются переотложенными. Данные отложения образовались в перигляциальных условиях ледниковой эпохи, когда существовала незамкнутая древесная растительность (пыльцы трав 40\%). Присутствие пыльцы Ephedra в начале разреза говорит даже о незамкнутой травянистой растительности. О неблагоприятных, холодных климатических условиях свидетельствует и присутствие недозрелой пыльцы, особенно среди пыльцы берез. Пыльца эта более мелкая, со стекловидным блеском, без четко выраженных слоев экзины и поровых отверстий.

Гораздо труднее судить о стратиграфическом ранге и положении данных отложений. Несмотря на значительную мощность осадков $(\sim 20$ м), в спорово-пыльцевых спектрах мы не наблюдаем полного исчезновения тундровых элементов, характерного для интерстадиалов.

Пыльца Betula nana L. встречается по всему разрезу, хотя отдельные минимумы ее отмечаются в интервалах 157,2-158,2 и 154,5-156,2 м (рис. 1 и 3). В названных интервалах не найдены споры тундровых плаунов и пыльца тундровых полыней (рис. 2,3 ). Но слишком большое количество пыльцы Betula nana L. $(20 \%)$ не позволяет считать эти интервалы интерстадиальными. Таким образом, по данным спорово-пыльцевого анализа мы наблюдаем чередование более холодных отрезков времени с некоторыми потеплениями, причем не придаем последним значения определенного стратиграфического ранга.

Мы уже знаем, сколько трудностей связано с выделением переотложенной пыльцы. Но как это ни странно, она может быть и полезной при определении возраста осадков. Возраст осадков можно определить по отношению к межледниковьям, т. е. установить, после какого межледниковья образовались данные отложения. При этом наиболее наглядные результаты получаются при построении вариограмм, предложенных В. Гричуком (рис. 4-9). На этих вариограммах, примененных впервые в данной работе, графически изображены количественные соот. ношения характернейших межледниковых компонентов, например ольхи, лещины, широколиственных пород. Строятся они следующим образом.

Вырисовываем координаты, например, для пыльцы ольхи и широколиственных пород с равными делениями на обеих координатах. Затем наносим каждый образец точкой, координатами которой является количество пыльцы ольхи и широколиственных пород в данном образце. Таким образом мы получаем совокупность точек, оконтуривание кото- 
рых дает конфигурацию, определенным образом расположенную относительно координат. Конфигурация эта называется вариограммой. Такие же вариограммы построим и для изображения количественных соотношений между пыльцой лещины и широколиственных пород, а также между пыльцой ольхи и лещины.

Построение вариограмм для разных межледниковых отложений позволяет обнаружить следующие закономерности для микулинского межледниковья (рис. $4,5,6$ ). Вариограмма пыльцы ольхи и широколиственных пород всегда держится ближе к оси ольхи, причем конфигурация ее в отношении этой оси перемещается в незначительных пределах. Связано это с тем, что количество пыльцы ольхи в микулинских межледниковых отложениях в несколько раз превышает количество пыльцы широколиственных пород. Вариограмма пыльцы лещины и широколиственных пород варьируется вблизи оси лещины. Конфигурация вариограммы пыльцы ольхи и лещины перемещается в отношении обеих координат примерно под углом $45^{\circ}$. Это объясняется сравнительно одинаковым количеством пьльцы ольхи и лешнны в микулинских межледниковых отложениях.

Иначе выглядят вариограммы лихвинских межледниковых отложений (рис. 7,8$)$. Если вариограмма пыльцы ольхи и широколиственных пород более или менее сходна с таковой микулинского межледниковья, то вариограмма пыльцы лещины и широколиственных пород имеет в значительной мере иной характер. Полученная конфигурация всегда держится ближе к оси широколиственных пород, а на вариограмме пыльцы ольхи и лещины она всегда прилегает к оси ольхи. Все это связано с бо́льшим количеством пыльцы ольхи по сравнению с лещиной в лихвинских межледниковых отложениях.

Таким образом, вариограммы этих двух межледниковий существенно отличаются.

Сравнение полученных вариограмм разреза Харимяэ (рис. 9) с вариограммами рассмотренных выше межледниковых отложений указывает на большое сходство их с вариограммами микулинских межледниковых отложений (рис. $4,5,6$ ), несмотря на сравнительно меньшее количество межледниковой пыльцы в разрезе Харимяэ по сравнению с типично межледниковыми разрезами. * Это указывает на присутствие пыльцы микулинского межледниковья в переотложенном виде в отложениях разреза Харимяэ, которые, видимо, образовались после микулинского межледниковья. Таким образом, приведенные выше данные не подтверждают высказанного ранее предположения о нижнеплейстоценовом возрасте отложений разреза Харимяэ, несмотря на то, что подошва их находится на сравнительно низкой абсолютной высоте $(+2 \mu)$ и сверху они перекрыты тремя моренными горизонтами (Каяк, Лийвранд, 1967).

Итак, варнограммы помогают нам определить возраст осадков. Конечно, более полезной в этом отношенни может быть пыльца, переотложенная из микулинских межледниковых отложений, по сравнению с более древними отложениями межледниковий. Метод вариограмм может дать хорошие результаты и при анализе моренных толщ, содержащих переотложенную пыльцу. Применение его все же ограничено. Пс-видимому, он даст хорошие результаты в основном для тех райо-

* Для отложекий одинцовского межледниковья вариограммы не составлены, так как в литературе не имеется соответствующнх цифровых данных, но можно думать, что они будут выглядеть совсем нначе, так как количество пыльцы широколиственных пород в этих отложениях превышает количество пыльцы ольхи и лещины (например, разрезы у пос. Подруднянского и дер. Глазово; см. Гричук, 1961). 
нов, где содержание пыльцы ольхи и лещины в межледниковых отложениях высокое, например на северо-западе Русской равнины. Во-вторых, лучшие результаты дают вариограммы лишь при наличии спор и пыльцы из одного межледниковья.

В итоге установлено, что изучаемые отложения разреза Харимяэ образовались в пернгляциальных условиях, по-видимому после микулинского межледниковья. Дальнеӥшие работы в этом направлении цолжны уточнить состав флоры и характер климатических условий, а также выяснить положение этих флор в пределах валдайского ледникового времени.

\section{Л И ТЕРА Т У Р А}

А н а н в а Е. Н. 1966. О недоразвитой пыльце в плейстоценовых отложениях. Бюлл. Комиссин по изуч. четверт, периода АН СССР, № 32.

Г ри чук В. П. 1961. Ископаемые флоры как палеонтологическая основа стратиграфии четвертичных отложений. В кн.: Рельеф и стратиграфия четвертичных отложекий северо-запада Русской равиины. М.

Г ричук. В. П. 1969. Значение палеоботанических материалов для разработки стратиграфии отложений эпохи валдайского оледенения (в печати).

К аяк К., Л и й р анд Э. 1967. О нижне- и среднеплейстоценовых отложениях Эстонии. В кн.: Нижний плейстоцек ледниковых районов Русской равнины. M.

М а л я со в а Е. С., К л ей м ен о в а Г. М. 1965. О палеоботанической характеристике лединовых и позднеледниковых отложений территории Ленинграда. В кн.: Проблемы палеогеографии. Л.

$\mathbb{C}$ укаче в B. Н. 1968. О растительности перигляциальных зон центральных частей Русской равнины. В кн.: История развития растительного покрова центральных областей европейской части СССР в антропогене. М.
Ннститут геологии
Академии наук Эстонской ССP
Поступила в редакцию
12/XII 1968

\section{E. LIIVRAND}

\section{FLORISTILISE ANALUUSI JA VARIOGRAMMIDE KASUTAMISEST SUIRAANALUUSI TULEMUSTE INTERPRETEERIMISEL HARIMÄE (LOUNA-EESTI) LÄBILŌIKE PŌHJAL}

Uheks raskeimaks probleemiks suiraanalüüsi tulemuste interpreteerimisel on ümbersettinud ja sünkroonse suira eraldamine, ilma milleta pole vōimalik teha őigeid järeldusi. Paremaid tulemusi annab seejuures floristiline analüüs, mis põhineb liikide täpsel ja küllaldasel hulgal määramisel őietolmu ja eoste järgi. Nende liikide ökoloogia ja geograafiline levik vôimaldavad selgitada, millised liigid vôisid koos kasvada, millised mitte. Juhindudes V. Gritšuki (1969) meetodeist, vōib Harimäe läbilōike suiraanalūüsi tulemustest järeldada, et uuritavad setted on kujunenud periglatsiaalsetes tingimustes, kuna suure hulga tundraliste liikide esinemine koos mõningate stepiliikidega on eriti iseloomulik just periglatsiaalsele floorale. Soojalembeste puude kasvamine nendes tingimustes polnud vōimalik ning nende puude õietolm on ümber settinud, mida tōendab ka selle ōietolmu korrapäratu esinemine setetes.

Setete vanuse määramisel kasutati variogramme, mis põhinevad tüüpilisemate jäävaheaegsete puude suhete graafilisel kujutamisel. Jälgiti lepa ja laialeheliste puude, sarapuu ja laialeheliste puude ja lepa ning sarapuu ôietolmuterade vahekorda. Harimäe läbilôike ümbersettinud suira variogrammid (joon. 9) sarnanevad kōige enam mikuulini jäävaheajale iseloomulike variogrammidega (joon. 4, 5, 6). Sellest lähtudes on need setted ilmselt kujunenud pärast mikuulini jäävaheaega. 


\section{E. LIIVRAND}

\section{OBER DIE VERWENDUNG DER FLORISTISCHEN ANALYSE UND DER METHODE DER VARIOGRAMME BEI DER INTERPRETATION DER RESULTATE DER POLLENANALYSE AUF GRUND DES PROFILS VON HARIMÃE (SUDESTLAND)}

Ein schwieriges Problem bei der Interpretation von Resultaten der Pollenanalyse ist das Abgrenzen der umgelagerten Pollen von synchronen, ohne was keine richtigen Folgerungen möglich sind.

Die besten Resultate zeigt die floristische Analyse, die sich auf einer genauen und genügenden Bestimmung der Pflanzenarten nach Pollen und Sporen gründet. Die Ökologie und geographische Verbreitung dieser Arten gestatten es, aufzuklären, welche Arten zusammen gedeihen können, welche nicht. Die Grundlagen der floristischen Analyse innerhalb der Pollenanalyse sind von V. P. Gritschuk (1969) ausgearbeitet worden. Sich nach dieser Arbeit richtend erlangte man das folgende Resultat der Pollenanalyse im Profil von Harimäe: die untersuchten Ablagerungen sind in periglazialen Bedingungen abgelagert worden. Eine große Menge Tundrapflanzen neben einigen Steppenpflanzen ist nämlich für die periglaziale Pflanzenwelt charakteristisch. Die wärmeliebenden Bäume könnten in solchen Bedingungen nicht gedeihen, so da B ihre Pollen umgelagert sind. Die Umlagerung wird auch durch die unregelmäBige Verbreitung der Pollen der Eichenmischwaldbäume in den Sedimenten nachgewiesen.

Zur Feststellung des Alters der Ablagerungen ist eine Variogramm-Methode benutzt worden, welche sich auf der Darstellung der Beziehungen zwischen typischen interglazialen Floraelementen gründet. Im vorliegenden Artikel werden die Beziehungen zwischen den Pollen der Erle und der Eichenmischwaldbäume, der Hasel und der Eichenmischwaldbäume, der Erle und der Hasel dargestellt (Abb. 4, 5, 6, 7, 8). Im Vergleich zu den interglazialen Variogrammen haben die Variogramme der umgelagerten Pollen von Harimäe (Abb. 9) eine große Ahnlichkeit mit den Variogrammen des Mikulino-Interglazials (Abb. $4,5,6)$. Auf Grund der Variogramme werden sich die entsprechenden Ablagerungen von Harimäe wohl erst nach der Mikulino-Interglazialzeit gebildet haben.

Die Pollenkurven der vorherrschenden Waldbäume werden übereinander (Abb. 1) und nebeneinander (Abb. 3) dargestellt. Die Menge des Pollens der Birkenarten wird aus der Summe der festgestellten Birkenarten (Abb. 1) und aus der Summe des Pollens der. Waldbäume (Abb. 3) errechnet. Auf Abb. 2 sind die Pollen und Sporen nach den ökologischen Gruppen eingeteilt. 